\title{
Active ingredients in Chinese medicines promoting blood circulation as $\mathrm{Na}^{+} / \mathrm{K}^{+}$-ATPase inhibitors
}

\author{
Ronald JY CHEN ${ }^{1}$, Tzyy-rong JINN², Yi-ching CHEN ${ }^{1}$, Tse-yu CHUNG ${ }^{1}$, Wei-hung YANG ${ }^{1,2}$, Jason TC TZEN ${ }^{1,2,3, *}$ \\ ${ }^{1}$ Graduate Institute of Biotechnology, National Chung Hsing University, Taichung 40227, Taiwan, China; ${ }^{2}$ School of Chinese Medicine, \\ China Medical University, Taichung 40402, Taiwan, China; ${ }^{3}$ Agricultural Biotechnology Research Center, Academia Sinica, Taipei \\ 11529, Taiwan, China
}

\begin{abstract}
The positive inotropic effect of cardiac glycosides lies in their reversible inhibition on the membrane-bound $\mathrm{Na}^{+} / \mathrm{K}^{+}-\mathrm{ATPase}$ in human myocardium. Steroid-like compounds containing a core structure similar to cardiac glycosides are found in many Chinese medicines conventionally used for promoting blood circulation. Some of them are demonstrated to be $\mathrm{Na}^{+} / \mathrm{K}^{+}$-ATPase inhibitors and thus putatively responsible for their therapeutic effects via the same molecular mechanism as cardiac glycosides. On the other hand, magnesium lithospermate $\mathrm{B}$ of danshen is also proposed to exert its cardiac therapeutic effect by effectively inhibiting $\mathrm{Na}^{+} / \mathrm{K}^{+}-\mathrm{ATPase}$. Theoretical modeling suggests that the number of hydrogen bonds and the strength of hydrophobic interaction between the effective ingredients of various medicines and residues around the binding pocket of $\mathrm{Na}^{+} / \mathrm{K}^{+}$-ATPase are crucial for the inhibitory potency of these active ingredients. Ginsenosides, the active ingredients in ginseng and sanqi, substantially inhibit $\mathrm{Na}^{+} / \mathrm{K}^{+}$-ATPase when sugar moieties are attached only to the $\mathrm{C}-3$ position of their steroid-like structure, equivalent to the sugar position in cardiac glycosides. Their inhibitory potency is abolished, however, when sugar moieties are linked to C-6 or C-20 position of the steroid nucleus; presumably, these sugar attachments lead to steric hindrance for the entrance of ginsenosides into the binding pocket of Na $/ \mathrm{K}^{+}-\mathrm{ATPase}$. Neuroprotective effects of cardiac glycosides, several steroid-like compounds, and magnesium lithospermate B against ischemic stroke have been accordingly observed in a cortical brain slice-based assay model, and cumulative data support that effective inhibitors of $\mathrm{Na}^{+} / \mathrm{K}^{+}$-ATPase in the brain could be potential drugs for the treatment of ischemic stroke.
\end{abstract}

Keywords: cardiac glycoside; ginsenoside; magnesium lithospermate B; neuroprotection; $\mathrm{Na}^{+} / \mathrm{K}^{+}$-ATPase inhibitors; blood circulation; steroid-like compound; traditional Chinese medicine

Acta Pharmacologica Sinica (2011) 32: 141-151; doi: 10.1038/aps.2010.197

\section{Introduction}

In an aging population cardiovascular diseases, such as congestive heart failure, have gradually become serious health challenges. Congestive heart failure, generally defined as incapability of the heart to supply sufficient blood flow to meet the body's needs, frequently leads to significantly adverse influences on physical and mental health, resulting in a markedly decreased quality of life and even death ${ }^{[1]}$. While cardiac glycosides, such as digoxin, digitoxin and ouabain, have been a cornerstone of the treatment of congestive heart failure for more than two centuries, severe side effects have been reported for these steroid-like compounds ${ }^{[2,3]}$. The narrow therapeutic index (the margin between effectiveness and toxicity) of cardiac glycosides further limits their clinical applications ${ }^{[4]}$. The limited benefit with certain side effects of

\footnotetext{
* To whom correspondence should be addressed.

E-mail TCTZEN@dragon.nchu.edu.tw

Received 2010-09-03 Accepted 2010-10-28
}

the existing remedies has prompted investigators to search for complementary and alternative therapies and drugs.

Many traditional Chinese medicines have long been used in the treatment of various cardiovascular diseases, such as coronary heart disease, heart stroke and myocardial infarction, and some of them are effective in promoting blood circulation, removing blood stasis and supplementing vital energy ${ }^{[5,6]}$. Although these medicines display considerable therapeutic effects with low toxicity, little is known about their primary active ingredients and detailed pharmaceutical mechanisms. Nevertheless, these traditional Chinese medicines, dating back 2000 years, have been regarded as valuable sources to screen potential drugs for the treatment of cardiovascular diseases.

With the rapid development of technology, numerous constituents in traditional Chinese medicines have been isolated and structurally determined ${ }^{[7]}$. Abundant steroid-like compounds, structurally similar to cardiac glycoside, have been found in many Chinese medicines used for promoting blood circulation $^{[8,9]}$. It is likely that these steroid-like compounds 
are responsible for the therapeutic effects of these medicines via the same molecular mechanism triggered by effective inhibition of $\mathrm{Na}^{+} / \mathrm{K}^{+}$-ATPase. On the other hand, no appreciable contents of steroid-like compounds are found in danshen (Salvia miltiorrhiza), a well-known Chinese herb traditionally regarded as an effective medicine for promoting blood circulation $^{[10]}$. Instead, magnesium lithospermate B (MLB), the major soluble ingredient in danshen, is assumed to be responsible for the therapeutic effect by inhibiting $\mathrm{Na}^{+} / \mathrm{K}^{+}$-ATPase in a manner comparable to that of cardiac glycosides.

This review summarizes recent research on $\mathrm{Na}^{+} / \mathrm{K}^{+}$-ATPase inhibitory potency of some active ingredients identified in the Chinese medicines used for promoting blood circulation. Molecular modeling and docking of these compounds to $\mathrm{Na}^{+} / \mathrm{K}^{+}$-ATPase resolve at molecular level the difference in their inhibitory potency. Potential usage of these active ingredients as inhibitors of $\mathrm{Na}^{+} / \mathrm{K}^{+}$-ATPase in the brain for the treatment of ischemic stroke is also discussed.

\section{Structure and function of $\mathrm{Na}^{+} / \mathrm{K}^{+}$-ATPase}

$\mathrm{Na}^{+} / \mathrm{K}^{+}$-ATPase, a P-type ATPase also known as sodium pump, is an active transport system of sodium and potassium ions that is highly conserved in all animal cells. It commonly consumes $20 \%-30 \%$ of the adenosine triphosphate (ATP) energy generated in animal cells at rest to actively transport three $\mathrm{Na}^{+}$out of and two $\mathrm{K}^{+}$into cells ${ }^{[11]}$. The X-ray crystal structure of $\mathrm{Na}^{+} / \mathrm{K}^{+}$-ATPase recently resolved ${ }^{[12-14]}$ shows that it is composed of three subunits ( $\alpha, \beta$ and $\gamma$ subunits) with distinct properties ${ }^{[15-17]}$; and the a catalytic subunit, a 112 $\mathrm{kDa}$ protein, contains sites important for ATP binding and phosphorylation as well as ion occlusion (Figure 1A) and an ouabain-binding site (Figure 1B), the primary binding site for many pharmacological agents, such as cardiac glycosides, that affect pump activity ${ }^{[18]}$.

Physiological functions of $\mathrm{Na}^{+} / \mathrm{K}^{+}$-ATPase have been deduced from its role as an ion pump. Specifically, the ability of $\mathrm{Na}^{+} / \mathrm{K}^{+}$-ATPase to establish and maintain ion gradients makes it essential for the generation and maintenance of electrical membrane potentials, which are necessary for neuronal excitability, transmission ${ }^{[19]}$ and cardiac muscle contraction ${ }^{[20]}$. $\mathrm{Na}^{+} / \mathrm{K}^{+}$-ATPase also generates the $\mathrm{Na}^{+}$gradient that is critical for the reabsorption of sodium ion and water from the glomerular filtrate in the nephron ${ }^{[21]}$ and absorption of fluid from the lungs and intestine ${ }^{[22]}$. It can also drive secondary active co-/countertransporters, which are coupled to the gradient of extracellular to intracellular $\mathrm{Na}^{+}$concentration, such as the sodium glucose cotransporter and the $\mathrm{Na}^{+} / \mathrm{Ca}^{2+}$ exchanger ${ }^{[23]}$. In addition, recent findings have suggested additional signaling modes of action of $\mathrm{Na}^{+} / \mathrm{K}^{+}$-ATPase ${ }^{[24-26]}$, implicating its regulation of several important cellular processes and highlighting potential therapeutic roles of its inhibitors (such as cardiac glycosides) in various diseases.

Inhibition of $\mathrm{Na}^{+} / \mathrm{K}^{+}$-ATPase by cardiac glycosides leading to a positive inotropic effect

Cardiac glycosides, such as ouabain and digoxin, are a diverse
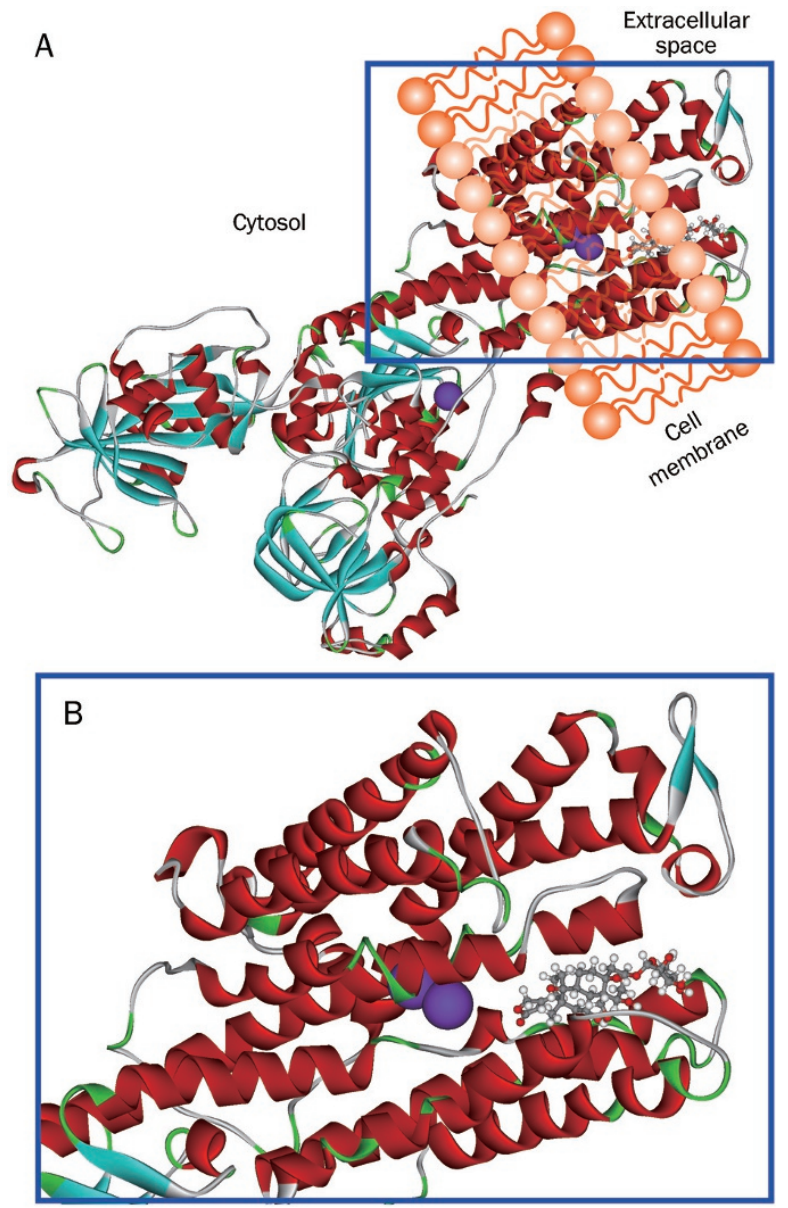

Figure 1. (A) Crystal structure of ouabain binding to the extracellular pocket of shark rectal gland $\mathrm{Na}^{+} / \mathrm{K}^{+}$-ATPase (PDB code $3 \mathrm{A3} Y$ ) $\alpha$ subunit ${ }^{[17]}$. Amino acid residues of $\mathrm{Na}^{+} / \mathrm{K}^{+}$-ATPase $\alpha$ subunit are shown in ribbon structure, and ouabain in scaled ball and stick. $\mathrm{K}^{+}$binding sites are shown in purple balls. (B) Enlarged diagram without the membrane bilayer shown in the blue box of (A).

family of naturally derived compounds that bind to and inhibit $\mathrm{Na}^{+} / \mathrm{K}^{+}$-ATPase. While they show considerable structural diversity, all members of this family share a common steroidal framework, regarded as the pharmacophoric moiety responsible for the activity of these compounds ${ }^{[27]}$. Generally, this steroid core is double-substituted with an unsaturated lactone ring at position 17 and a sugar portion at position 3; and this lactone moiety of cardiac glycosides is critical for their potent inhibition of $\mathrm{Na}^{+} / \mathrm{K}^{+}$-ATPase. Although the sugar moiety does not greatly influence their biological activity, the addition of sugars to the steroid core affects the pharmacodynamic and pharmacokinetic profile of each glycoside ${ }^{[28]}$.

Cardiac glycosides have been in clinical use for many years for the treatment of congestive heart failure and cardiac arrhythmia, and the mechanism of their positive inotropic effect is well characterized. According to the most widely accepted molecular mechanism responsible for the therapeutic effect of cardiac glycosides, they act through reversible inhibition of $\mathrm{Na}^{+} / \mathrm{K}^{+}$-ATPase in the membrane of heart muscle 
cells ${ }^{[29,30]}$. In human heart, inhibition of the $\mathrm{Na}^{+} / \mathrm{K}^{+}$-ATPase leads to the accumulation of intracellular sodium ion, which decreases the sodium gradient across the membranes of cardiac muscle cells. This reduced sodium gradient in turn limits the activity of the $\mathrm{Na}^{+} / \mathrm{Ca}^{2+}$ exchanger in the cell membrane, which normally uses the sodium gradient for energy in the extrusion of calcium ion ${ }^{[31]}$. Each cardiac action potential is thus followed by elevated levels of residual intracellular calcium ion, and the net effect of which is to strengthen successive heart contractions ${ }^{[32]}$. In this way, inhibition of the $\mathrm{Na}^{+} / \mathrm{K}^{+}$-ATPase by cardiac glycosides produces beneficial effects in patients with congestive heart failure. However, severe side effects and narrow therapeutic index of cardiac glycosides have apparently limited their clinical applications $^{[29]}$.

\section{Steroid-like compounds in Chinese medicines for promoting blood circulation and their inhibitory potency on $\mathrm{Na}^{+} / \mathrm{K}^{+}$-ATPase}

Many Chinese medicinal products traditionally used in the treatment of cardiovascular diseases seem to achieve their therapeutic effects via promotion of blood circulation. A number of steroid-like compounds, such as triterpenoids, steroids and saponins, have been found in Chinese medicinal products used for promoting blood circulation (Table 1), and regarded as the active ingredients responsible for their therapeutic effects ${ }^{[33-64]}$. In light of the structural similarity between the core structure of these steroid-like compounds and the steroidal framework of cardiac glycosides, we propose that some of these medicines may possess therapeutic effects via inhibition of $\mathrm{Na}^{+} / \mathrm{K}^{+}$-ATPase by their steroid-like compounds ${ }^{[65]}$. Some of the steroid-like compounds listed in Table 1 are commercially available and thus subjected to $\mathrm{Na}^{+} /$ $\mathrm{K}^{+}$-ATPase inhibition assay (Figure 2). The results show that all examined steroid-like compounds found in Chinese medicines for promoting blood circulation displayed more or less inhibitory potency on $\mathrm{Na}^{+} / \mathrm{K}^{+}$-ATPase. Among these steroidlike compounds, bufalin (structurally almost equivalent to ouabain) exhibits significantly higher inhibitory potency $\left(\mathrm{IC}_{50}\right.$ value around $1 \mu \mathrm{mol} / \mathrm{L}$ ) than the others while ginsenoside $\mathrm{Rh} 2$, ursolic acid and oleanolic acid are relatively moderate inhibitors of $\mathrm{Na}^{+} / \mathrm{K}^{+}$-ATPase with $\mathrm{IC}_{50}$ values around $50-100$ $\mu \mathrm{mol} / \mathrm{L}$. Based on the experimental observation of inhibitory potency of steroid-like compounds on $\mathrm{Na}^{+} / \mathrm{K}^{+}$-ATPase, the therapeutic effects of many cardiac Chinese medicines may be partly attributed to various steroid-like compounds that promote blood circulation via the same molecular mechanism triggered by cardiac glycosides, that is, accentuating the force of myocardial contraction by elevating calcium concentration via the inhibition of $\mathrm{Na}^{+} / \mathrm{K}^{+}$-ATPase.

\section{Inhibition of $\mathrm{Na}^{+} / \mathrm{K}^{+}$-ATPase by MLB, a non-steroid} compound, leading to the therapeutic effect of danshen

Danshen, the dried roots of medicinal plant Salvia miltiorrhiza, is one of the most popular Chinese medicines widely used in many medicinal preparations and formulae taken by people in several Asian countries. Traditionally it is regarded as an effective herb for promoting blood circulation, removing blood stasis, relieving pain, stimulating menstrual discharge, and relaxing the mind. Therefore, danshen has also been extensively used in the treatment of coronary heart disease, myocardial infarction, heart failure, menstrual disorders, and

Table 1. Steroid-like compounds in Chinese medicines used for the promotion of blood circulation.

\begin{tabular}{|c|c|c|}
\hline Compound & Chinese medicinal sources & References \\
\hline Bufalin & The dried venom of Bufo bufo gargarizans Cantor or B bufo melanostictua Schneider & 33,34 \\
\hline Ginsenoside Rh2 & The dry root of Panax ginseng or $P$ notoginseng $\mathrm{F} \mathrm{H}$ Chen & $35-37$ \\
\hline Ursolic acid & Whole plant of Prunella vulgaris $L$ with dry flowers & 38,39 \\
\hline Oleanolic acid & Whole plant of Prunella vulgaris L with dry flowers & 38,39 \\
\hline Saikosaponin A & The dry root of Bupleurum chinense DC or B scorzonerifolium Willd & 40,41 \\
\hline Polygalacic acid & The dry root of Platycodon grandiflorum (Jacq) A DC & 45 \\
\hline Jujuboside B & The mature seeds of Ziziphus jujube Mill var spinosa (Bunge) Hu ex H F Chou & 46 \\
\hline Glycyrrhizin & The root of Glycyrrhiza uralensis Fisch - G inflata Bat or G glabra L & 47,48 \\
\hline Astragaloside III & The dry root of Astragalus membranaceus (Fisch) Bge or var mongholicus (Bge) Hsiao & 49 \\
\hline Betulinic acid & The dried root cortex of Paeonia suffruticosa & 50 \\
\hline Inokosterone & The dry root of Achyranthes bidentata Blume & 51 \\
\hline Cucurbitacin D & The fruit of Trichosanthes kirilowii Maxim or T rosthornii Harms & 59,60 \\
\hline$\beta$-Boswellic acid & The oleogum resin of Boswellia carterii Birdwood & 61 \\
\hline Isolimonoic acid & The fruit of Citrus aurantium $\mathrm{L}$ & 62 \\
\hline$\beta$-Sitosterol & The rhizome of Sparganium stoloniferum Buch-Ham & 63 \\
\hline Pachymic acid & The sclerotium of Poria cocos (Schw) Wolf & 64 \\
\hline
\end{tabular}


A<smiles>C[C@]12C[C@H](O)[C@H](C3=CC(=O)OC3)CC[C@]1(O)C1CC[C@]3(O)C[C@@H](Oc4ccccc4)C[C@H](O)[C@@]3(CO)C12</smiles><smiles>C[C@]12CC[C@@H](O)CC1CCC1CC[C@]3(C)[C@H](c4ccc(=O)oc4)CC[C@]3(O)C12</smiles>

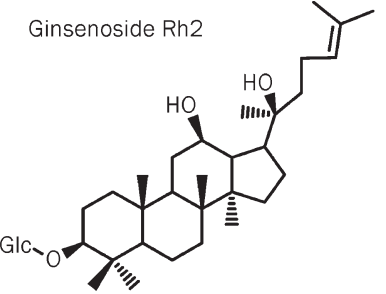

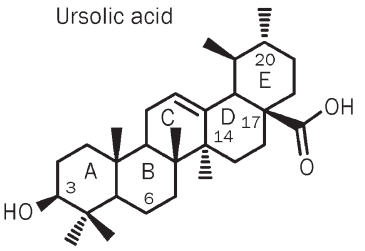<smiles>C[C@@H]1C[C@@]2(C(=O)O)CC[C@]3(C)C(=CCC4[C@]3(C)CCC3C(C)(C)[C@H](O)CC[C@@]34C)C2CC1(C)C</smiles>

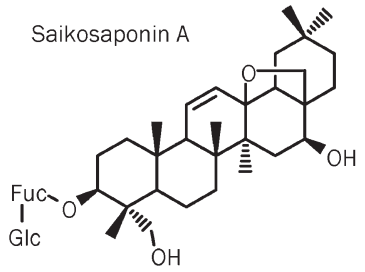<smiles>C[C@H](CCC(=O)O)C1CCC2C1[C@@H](O)CC1C2[C@H](O)CC2C[C@H](O)CC[C@@]21C</smiles>

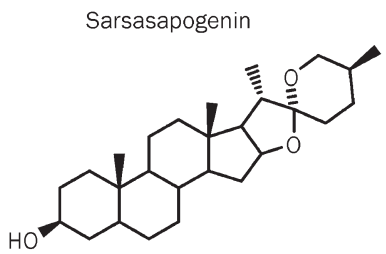

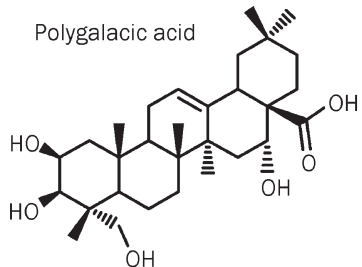

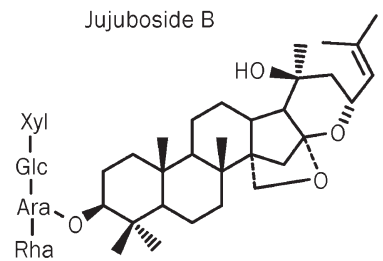

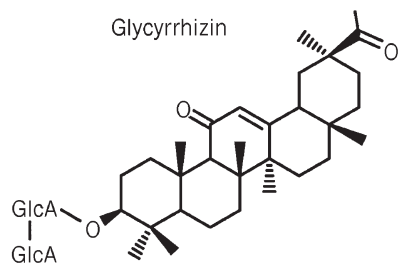

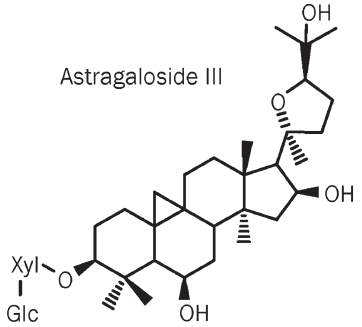

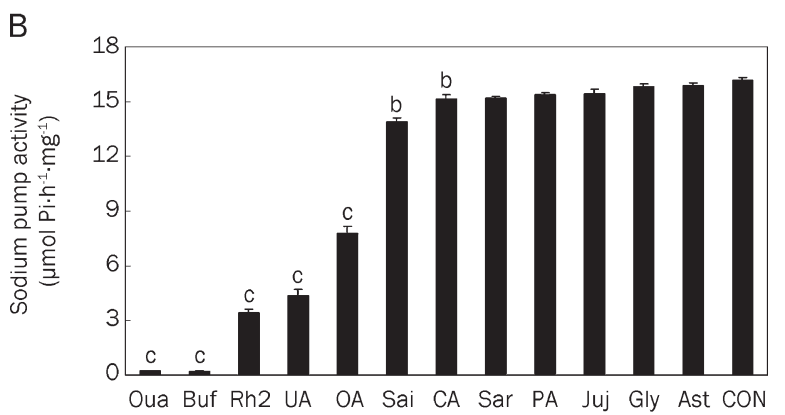

other cerebrovascular diseases ${ }^{[66]}$. Ingredients in danshen are mainly divided into water-soluble and lipid-soluble compounds. Although some lipid-soluble constituents in this herb, such as tanshinones, have been conventionally considered the active ingredients ${ }^{[67,68]}$, the major water-soluble component MLB, a derivative of caffeic acid tetramer, recently has also been demonstrated to possess several medicinal effects, such as vasodilating, antihypertensive, antioxidative, and free radical scavenging activities ${ }^{[69-73]}$. MLB possesses a relatively rigid structure due to the formation of salt bridges between $\mathrm{Mg}^{2+}$ and the four oxygen atoms of carboxyl groups from the four caffeic acid fragments.
Figure 2. (A) Chemical structures of ouabain and 11 steroid-like compounds found in Chinese medicinal products used for the promotion of blood circulation. (B) Inhibition of porcine $\mathrm{Na}^{+} / \mathrm{K}^{+}$ATPase by $0.1 \mathrm{mmol} / \mathrm{L}$ of ouabain and the selected 11 steroid-like compounds. Data represent mean \pm SEM of 5 replicates. ${ }^{b} P<0.05$, ${ }^{\mathrm{C}} P<0.01$ vs control group (CON: deionized water only). (Adopted and modified from Figures 1 and 2 of Chen et al, Acta Pharmacol Sin 2010; 31: 696-702).

In spite of being a non-steroid compound, MLB possesses potent inhibition on $\mathrm{Na}^{+} / \mathrm{K}^{+}$-ATPase in vitro ${ }^{[74]}$. The molecular organization and configuration of MLB in the 3D structure is somewhat similar to ouabain, a cardiac glycoside with a rigid steroid backbone (Figure 3A), although they are totally different compounds with distinct molecular weights (584.65 for ouabain and 740.67 for MLB). Based on experimental observation and theoretical modeling, we propose that MLB acts as the active component responsible for the cardiac therapeutic effect of danshen by the same molecular mechanism triggered by cardiac glycosides, ie, inhibition of $\mathrm{Na}^{+} / \mathrm{K}^{+}$-ATPase (Figure $3 \mathrm{~B})$. In agreement with this proposal, the intracellular $\mathrm{Ca}^{2+}$ 
A

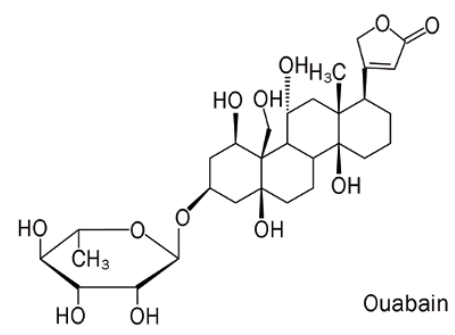

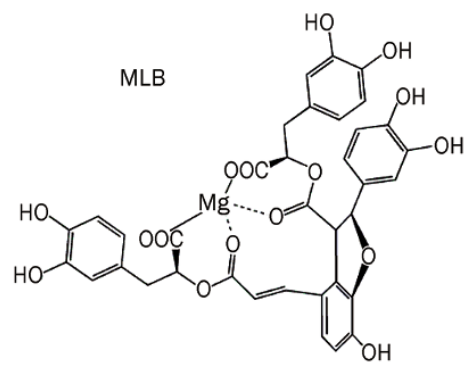
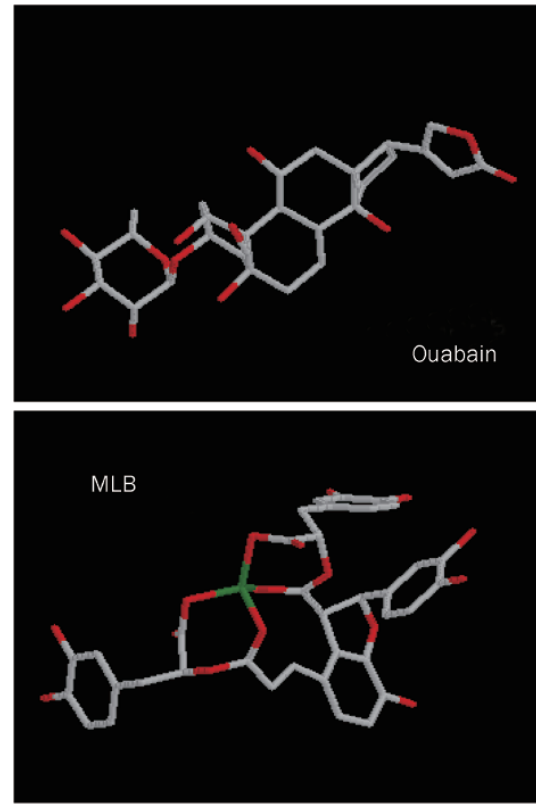

B

(Exchange of $\mathrm{Na}^{+}$with $\mathrm{Ca}^{2+}$ )

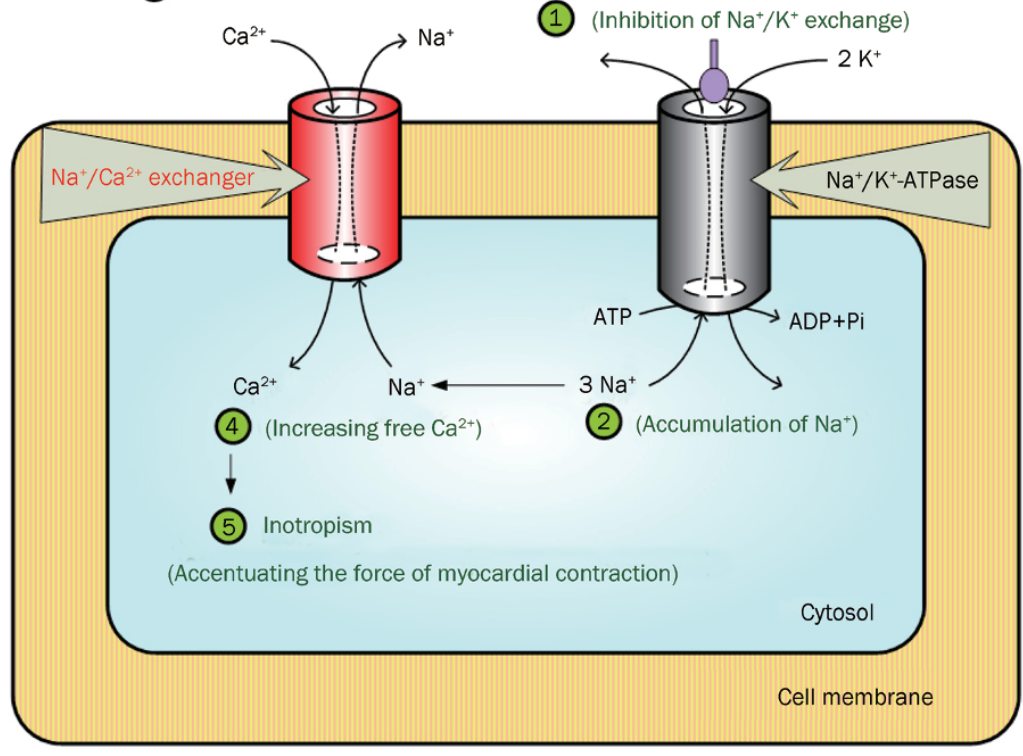

Extracellular space
Figure 3. (A) Chemical structures of ouabain and MLB. The 3D structures of ouabain and MLB (in dark background) were displayed using RasWin Molecular Graphics Windows Version 2.6. Gray, red, and green colors represent $\mathrm{C}, \mathrm{O}$, and $\mathrm{Mg}^{2+}$ atoms, respectively. (B) Proposed molecular mechanism responsible for the therapeutic effects of cardiac glycosides, ginsenosides, MLB, and other steroid-like compounds in cardiac cells. Step 1: Inhibiting the cellular exchange of $\mathrm{Na}^{+}$and $\mathrm{K}^{+}$by drugs binding to $\mathrm{Na}^{+} / \mathrm{K}^{+}$-ATPase. Step 2: Accumulation of $\mathrm{Na}^{+}$in the intracellular space due to the inhibition of $\mathrm{Na}^{+} / \mathrm{K}^{+}$-ATPase activity. Step 3: Promotion of the cellular exchange of $\mathrm{Na}^{+}$and $\mathrm{Ca}^{2+}$ via the $\mathrm{Na}^{+} / \mathrm{Ca}^{2+}$ exchanger system. Step 4: Increasing the intracellular $\mathrm{Ca}^{2+}$ concentration owing to the activation of the $\mathrm{Na}^{+} / \mathrm{Ca}^{2+}$ exchanger system. Step 5: The elevated intracellular $\mathrm{Ca}^{2+}$ concentration leads to an increased inotropism and accentuates the force of myocardial contraction. (Adopted from Figure 1 and the cover page of Tzen et al, Acta Pharmacol Sin 2007; 28: 609-15). levels of SH-SY5Y neuroblastoma cells treated with MLB are substantially elevated in a manner similar to that observed in cells treated with ouabain ${ }^{[75]}$. The elevated $\mathrm{Ca}^{2+}$ levels seem to be supplied by both extracellular influx through the $\mathrm{Na}^{+} / \mathrm{Ca}^{2+}$ exchanger and intracellular release from endoplasmic reticulum.

Cell toxicity caused by cardiac glycosides at high concentrations has been noticed and blamed to their putative triggering of several signaling cascade responses that lead to cell death ${ }^{[76]}$. In contrast, MLB is generally regarded as an antioxidant without notable toxicity ${ }^{[74]}$. Similar results were found in our studies: severe cell toxicity accompanied with dendritic shrink was observed in SH-SY5Y cells treated with ouabain, but not in those treated with MLB $^{[75]}$. Therefore, we surmise that MLB has a great potential, with extensive clinical trials, to become a safer drug than cardiac glycosides.

\section{Molecular modeling: the binding mode of potential inhibitors to $\mathrm{Na}^{+} / \mathrm{K}^{+}$-ATPase}

Molecular modeling and docking of steroid-like compounds and MLB to the a subunit of $\mathrm{Na}^{+} / \mathrm{K}^{+}$-ATPase revealed the observed difference in their $\mathrm{Na}^{+} / \mathrm{K}^{+}$-ATPase inhibition at molecular level. The drastic difference observed in the inhibitory potency of these active ingredients is ascribed mainly to the number of hydrogen bonds (H-bonds) and partially to the strength of hydrophobic interaction between the com- 
pounds and residues around the deep cavity close to the two $\mathrm{K}^{+}$binding sites of $\mathrm{Na}^{+} / \mathrm{K}^{+}$-ATPase (Figure 4). As expected from structural similarity, the interaction of bufalin with the binding pocket of $\mathrm{Na}^{+} / \mathrm{K}^{+}$-ATPase nearly matched to that of ouabain reported previously ${ }^{[16]}$ with the unique lactone ring penetrating deeply into the cavity close to two $\mathrm{K}^{+}$binding sites. For ouabain, three $\mathrm{H}$-bonds are formed between the lactone ring and Ile328 and Ala330 of $\mathrm{Na}^{+} / \mathrm{K}^{+}$-ATPase, and two $\mathrm{H}$-bonds between the hydroxyl group at C-14 and Thr804 of $\mathrm{Na}^{+} / \mathrm{K}^{+}$-ATPase. In contrast, one $\mathrm{H}$-bond is formed between the lactone ring of bufalin and Ala330 of $\mathrm{Na}^{+} / \mathrm{K}^{+}$-ATPase, and two H-bonds between the hydroxyl group at C-14 of bufalin and Thr804 of $\mathrm{Na}^{+} / \mathrm{K}^{+}$-ATPase. Two H-bonds are formed between the hydroxyl groups at C-12 and C-20 of ginsenoside Rh2 and Asn129 and Thr804 of $\mathrm{Na}^{+} / \mathrm{K}^{+}$-ATPase, respectively. Strong hydrophobic interaction is found between the lactone ring of ouabain or bufalin and six hydrophobic residues (Ile327, Ile328, Val329, Ile787, Phe790, and Ile807) around the deep cavity of $\mathrm{Na}^{+} / \mathrm{K}^{+}$-ATPase. A hydrophobic interaction between the alkyl group of ginsenoside Rh2 and the same six hydrophobic residues of $\mathrm{Na}^{+} / \mathrm{K}^{+}$-ATPase is also found. Only one $\mathrm{H}$-bond is formed between the carboxyl group of ursolic acid and Ile322 of $\mathrm{Na}^{+} / \mathrm{K}^{+}$-ATPase, and a moderate hydrophobic interaction is found between the ring $\mathrm{E}$ of ursolic acid and four hydrophobic residues (Ile327, Val329, Phe790, and Ile807) of $\mathrm{Na}^{+} / \mathrm{K}^{+}$-ATPase. On the whole, no $\mathrm{H}$-bond is formed between those steroid-like compounds with weak inhibitory potency and the binding pocket of $\mathrm{Na}^{+} / \mathrm{K}^{+}-\mathrm{ATPase}^{[65]}$. However, hydrophobic interaction of similar strength is observed between the hydrophobic steroidal core of all 12 steroidlike compounds examined and 8 other hydrophobic residues (Leu132, Tyr315, Ile322, Phe323, Ile325, Phe793, Ile794, and Leu802 located in the upper portions of the figures) around the binding pocket of $\mathrm{Na}^{+} / \mathrm{K}^{+}$-ATPase.

Three H-bonds are formed between the hydroxyl group at C-4 position of MLB and Lys912 (forming two H-bonds) and Glu915 (forming one $\mathrm{H}$-bond) of $\mathrm{Na}^{+} / \mathrm{K}^{+}$-ATPase, one $\mathrm{H}$-bond between the carbonyl group at C-9 position of MLB and Thr804 of $\mathrm{Na}^{+} / \mathrm{K}^{+}$-ATPase, and one $\mathrm{H}$-bond between the hydroxyl group at C-4 position of MLB and Leu110 of $\mathrm{Na}^{+} / \mathrm{K}^{+}$-ATPase. Similar to the hydrophobic steroidal core of ouabain, the four aromatic rings of MLB form strong hydrophobic interaction with hydrophobic residues (Leu132, Tyr315, Ile322, Phe323, Ile325, Phe793, Ile794, and Leu802) around the binding pocket of $\mathrm{Na}^{+} / \mathrm{K}^{+}$-ATPase.

\section{Effects of different sugar attachments to ginsenosides on $\mathrm{Na}^{+} / \mathrm{K}^{+}$-ATPase inhibitory potency}

Ginsenosides are triterpenoidal saponins that have a common four ring hydrophobic steroid-like structure with various sugar moieties attached mostly at the C-3, C-6, or C-20 position (Figure 5). To date, more than 80 ginsenosides have been isolated from over ten Panax taxa, and most of them are derived from four types of aglycones: protopanaxadiol, protopanaxatriol, oleanolic acid, and ocotillol ${ }^{[7]}$. Several biological activities, such as neuroprotective effects, antitumour activity, and cardiac therapeutic effects, have been documented for many ginsenosides $^{[78,79]}$. Ginsenosides have also been regarded as the active ingredients in many Chinese herbs, for instance, ginseng and sanqi (the roots of Panax ginseng and Panax notoginseng), two well-known traditional Chinese herbs commonly used for the treatment of coronary heart disease and cerebral vascular disease ${ }^{[80-82]}$.

Based on experimental observation and theoretical modeling, the therapeutic effects of ginseng and sanqi in promoting blood circulation should be at least partly attributed to the effective inhibition of $\mathrm{Na}^{+} / \mathrm{K}^{+}$-ATPase by ginsenosides ${ }^{[83]}$, such as ginsenoside Rh2. However, different sugar moieties in ginsenosides affect their inhibitory potency on $\mathrm{Na}^{+} / \mathrm{K}^{+}$-ATPase. In our study, ginsenosides with sugar moieties attached only to the C-3 position of the steroid-like structure, equivalent to the sugar position in cardiac glycosides, possess inhibitory potency on $\mathrm{Na}^{+} / \mathrm{K}^{+}$-ATPase. However, their inhibitory potency is significantly reduced or completely abolished when a monosaccharide was linked to the C- 6 or C-20 position of the steroid-like structure; the inhibitory potency is lost completely when the monosaccharide is replaced by a disaccharide molecule at either positions. Molecular modeling and docking show that sugar attachment to the C- 6 or C-20 position of the steroid-like structure apparently causes steric hindrance to the entrance of ginsenosides into the extracellular binding pocket of the $\mathrm{Na}^{+} / \mathrm{K}^{+}$-ATPase a subunit, and thus greatly reduces or completely abolishes their inhibitory potency.

Paradoxically, most ginsenosides found in ginseng and sanqi do not seem to be competent inhibitors of $\mathrm{Na}^{+} / \mathrm{K}^{+}$-ATPase due to their sugar attachment to the C- 6 or C-20 position of the steroid-like structure. Nevertheless, ginsenosides might act as prodrugs, as they tend to be metabolized to their active forms by intestinal bacterial deglycosylation after oral administration ${ }^{[84]}$. Generally, the metabolites, easily absorbed by the intestines due to an increase of hydrophobicity after deglycosylation, might display the same or different pharmacological actions in comparison with their parent compounds ${ }^{[85]}$. Therefore, the cardiac therapeutic effects of ginseng and sanqi could very possibly be attributed to the effective inhibition of $\mathrm{Na}^{+} / \mathrm{K}^{+}$-ATPase by the metabolized ginsenosides, with sugar moieties attached only to the C-3 position of the steroid-like structure.

\section{Combinational usage of danshen and sanqi for the treatment of cardiovascular diseases}

In contrast with Western medicines, combinational usage of traditional Chinese medicines with similar or different therapeutic effects is a common practice. Currently, several commercial products for cardiovascular diseases comprise mainly danshen and sanqi in variable ratios, mostly with danshen as the major and sanqi the minor constituents ${ }^{[86]}$. The active ingredients in danshen and sanqi for cardiac therapeutic effects are MLB and ginsenosides, respectively. MLB, a polyphenolic compound, is metabolized within a few hours after consumption ${ }^{[87]}$. In contrast, it takes a couple of days to metabolize the steroid-like ginsenosides in human body ${ }^{[88,89]}$. 

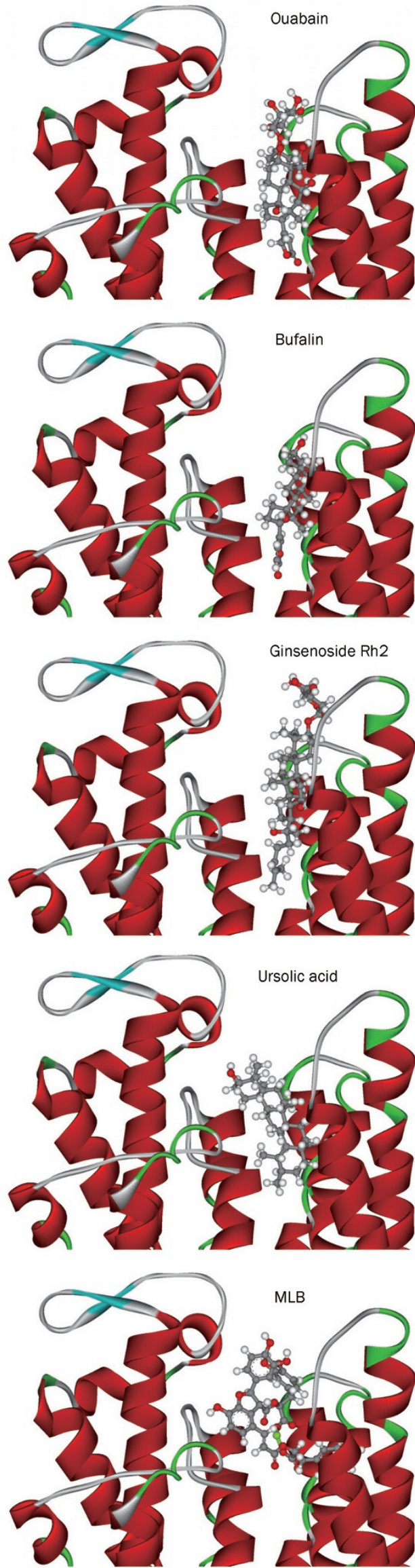
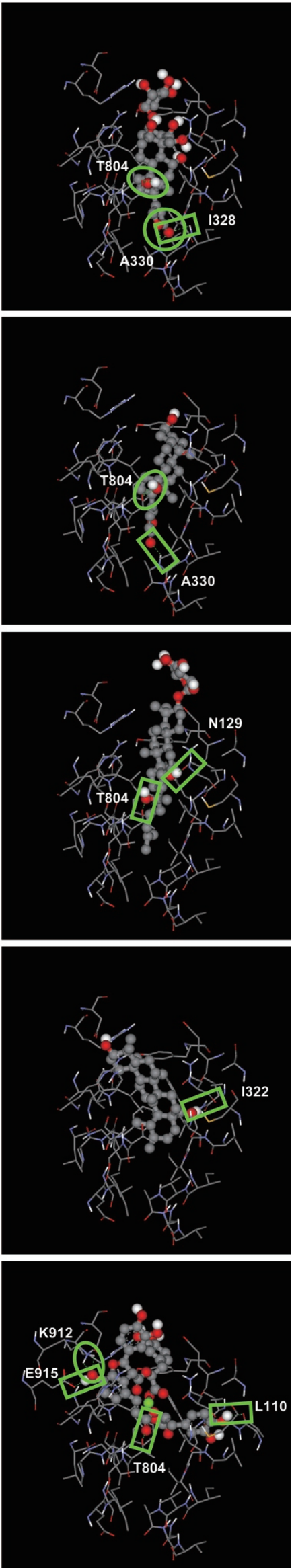

Figure 4. Detailed molecular interactions between the extracellular binding pocket of $\mathrm{Na}^{+} / \mathrm{K}^{+}$-ATPase and ouabain, bufalin, ginsenoside Rh2, ursolic acid, or MLB. (Left panels) Modeling is displayed for ligand compounds, ouabain, bufalin, ginsenoside Rh2, ursolic acid, and MLB binding to the extracellular pocket of $\mathrm{Na}^{+} / \mathrm{K}^{+}$ATPase $\alpha$ subunit. Amino acid residues around the binding pocket of $\mathrm{Na}^{+} / \mathrm{K}^{+}$-ATPase are shown in ribbon structure, and ligand compounds in stick structure. (Right panels) Amino acid residues of $\mathrm{Na}^{+} / \mathrm{K}^{+}$-ATPase close to ligand compounds (balland-stick structure) are shown in line structure. Green box or oval represents one or two hydrogen bonds formed between $\mathrm{Na}^{+} / \mathrm{K}^{+}$-ATPase and ligand compounds. (Adopted and modified from Figure 6 of Chen et al, Acta Pharmacol Sin 2010; 31: 696702 and Figure 5 of Chen et al, Acta Pharmacol Sin 2010; 31: 923-9). 


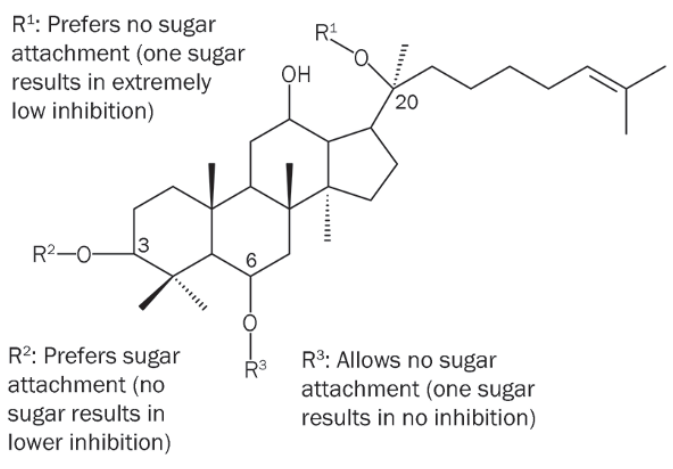

Figure 5. A summarized diagram for the effects of sugar attachments in three different positions of the steroid nucleus of ginsenosides. Detailed 3D diagrams are shown in Figures 4, 5, and 6 of Chen et al, Acta Pharmacol Sin 2009; 30: 61-9.

In light of our recent studies, we rationalize that the combinational usage of danshen and sanqi for the treatment of cardiovascular diseases takes the advantages of the non-toxic and yet strong $\mathrm{Na}^{+} / \mathrm{K}^{+}$-ATPase inhibitory potency of MLB to relieve the symptoms promptly and the moderate $\mathrm{Na}^{+} / \mathrm{K}^{+}$-ATPase inhibitory potency of ginsenosides to provide a relatively long-term basal therapeutic effect.

\section{Inhibition of $\mathrm{Na}^{+} / \mathrm{K}^{+}$-ATPase and its potential neuro- protection}

In brain cells, approximately half of all energy is spent for the active exchange of cytosolic sodium for extracellular potassium, a process carried out by $\mathrm{Na}^{+} / \mathrm{K}^{+}$-ATPase for the maintenance of transmembrane ionic gradients for all mammalian cells ${ }^{[90-92]}$. As the brain's primary consumer of ATP, $\mathrm{Na}^{+} / \mathrm{K}^{+}$-ATPase is particularly vulnerable to ATP depletion commonly observed in ischemic stroke. This vulnerability suggests that pharmacological inhibition of the $\mathrm{Na}^{+} / \mathrm{K}^{+}$-ATPase in brain cells should further compromise ATP-depleted neurons. Indeed, there is accumulating evidence that inhibiting the brain $\mathrm{Na}^{+} / \mathrm{K}^{+}$-ATPase can actually provide neuroprotection in the context of ischemia ${ }^{[33]}$.

Cardiac glycosides, being potent inhibitors of $\mathrm{Na}^{+} / \mathrm{K}^{+}-$ ATPase, have been demonstrated to provide neuroprotection against ischemic stroke in a cortical brain slice-based compound screening platform ${ }^{[94]}$. Moreover, it has been hypothesized that blockade of $\mathrm{Na}^{+} / \mathrm{K}^{+}$-ATPase may provide neuroprotective effect in ischemia-reperfusion through ATP conservation and modulating intracellular calcium levels just as the cardiac glycosides do in the heart contraction cycle ${ }^{[93]}$. Similar neuroprotective effects have also been documented for ginsenosides against ischemic stroke, and some of the results were observed using the same brain slice assay model ${ }^{[95-99]}$. Oleanolic acid, a steroid-like compound and moderate inhibitor of $\mathrm{Na}^{+} / \mathrm{K}^{+}$-ATPase, also displayed neuroprotective effect against focal cerebral ischemic injury ${ }^{[100]}$. Furthermore, the same phenomenon was observed when we examined the neuroprotective effect of MLB against ischemic stroke in a similar brain slice assay model ${ }^{[74]}$. Taken together, these experimental data support that inhibiting $\mathrm{Na}^{+} / \mathrm{K}^{+}$-ATPase may provide neuroprotection in the context of ischemia as well as other neurodegenerative conditions. It is more than likely that effective inhibitors of $\mathrm{Na}^{+} / \mathrm{K}^{+}$-ATPase in the brain are potential drugs for the treatment of ischemic stroke.

\section{Conclusions and perspectives}

With a history of at least 2000 years, traditional Chinese medicines have long been regarded as precious resources for screening new drugs. Our recent studies have shown that steroid-like compounds in many Chinese medicines used for promoting blood circulation display more or less inhibitory potency on $\mathrm{Na}^{+} / \mathrm{K}^{+}$-ATPase, and may thus provide the therapeutic effects of corresponding medicines via the same molecular mechanism triggered by cardiac glycosides. Except bufalin in ChanSu, steroid-like compounds in traditional Chinese medicines used for promoting blood circulation are expected to exert less severe side effects than cardiac glycosides. Nevertheless, side effects have to be expected of a continuous consumption of these steroid-like compounds for a long period of time. In contrast, MLB, the non-steroid active ingredient responsible for the cardiac therapeutic effect of danshen by effective inhibition of $\mathrm{Na}^{+} / \mathrm{K}^{+}$-ATPase, is generally regarded as a non-toxic antioxidant without apparent adverse effects. Therefore, we believe that MLB is of great potential to replace cardiac glycosides for the treatment of congestive heart failure, provided it undergoes necessary clinical trials. Moreover, searching from traditional Chinese medicines for additional antioxidant polyphenolic compounds possessing inhibitory potency on $\mathrm{Na}^{+} / \mathrm{K}^{+}$-ATPase may lead to the discovery of novel drugs for the treatment of cardiovascular diseases without side effects.

\section{Acknowledgements}

Project supported by a grant to Jason TC TZEN from the National Science Council, Taiwan, China (No 96-2752-B-005008-PAE).

We thank Prof Chih-ning SUN (Department of Entomology, National Chuang Hsing University, China) for critical reading of the manuscript.

\section{References}

1 Boxer R, Yang SX, Hager WD. Congestive heart failure and the elderly. Conn Med 2003; 67: 497-503.

2 Haustein KO. Cardiotoxicity of digitalis. Arch Toxicol Suppl 1986; 9: 197-204.

3 Koren G, Woodland C, Ito S. Toxic digoxin-drug interactions: the major role of renal P-glycoprotein. Vet Hum Toxicol 1998; 40: 45-6.

4 Vivo RP, Krim SR, Perez J, Inklab M, Tenner T Jr, Hodgson J. Digoxin: current use and approach to toxicity. Am J Med Sci 2008; 336: 423-8.

5 Gong X, Sucher NJ. Stroke therapy in traditional Chinese medicine (TCM): prospects for drug discovery and development. Phytomedicine 2002; 9: 478-84.

6 Liang $\mathrm{H}$, Chen S, Shen S. Clinical observation on influence of Chinese medicines for promoting blood circulation to remove blood stasis on FIB and DD in plasma of patients with cerebral thrombosis. 
J Tradit Chin Med 2002; 22: 256-9.

7 Yang M, Sun J, Lu Z, Chen G, Guan S, Liu X, et al. Phytochemical analysis of traditional Chinese medicine using liquid chromatography coupled with mass spectrometry. J Chromatogr A 2009; 1216: 2045-62.

8 Liu XX, Wang L, Chen XQ, Deng XT, Cao Y, Wang Q. Simultaneous quantification of both triterpenoid and steroidal saponins in various Yunnan Baiyao preparations using HPLC-UV and HPLC-MS. J Sep Sci 2008; 31: 3834-46.

9 Zhang Q, Ye M. Chemical analysis of the Chinese herbal medicine Gan-Cao (licorice). J Chromatogr A 2009; 1216: 1954-69.

10 Wang X, Morris-Natschke SL, Lee KH. New developments in the chemistry and biology of the bioactive constituents of Tanshen. Med Res Rev 2007; 27: 133-48.

11 Skou JC, Esmann M. The Na, K-ATPase. J Bioenerg Biomembr 1992; 24: 249-61.

12 Shinoda T, Ogawa H, Cornelius F, Toyoshima C. Crystal structure of the sodium-potassium pump at $2.4 \AA$ resolution. Nature 2009; 459: 446-50.

13 Morth JP, Pedersen BP, Toustrup-Jensen MS, Sorensen TL, Petersen J, Andersen JP, et al. Crystal structure of the sodium-potassium pump. Nature 2007; 450: 1043-9.

14 Ogawa H, Shinoda T, Cornelius F, Toyoshima C. Crystal structure of the sodium-potassium pump $\left(\mathrm{Na}^{+}, \mathrm{K}^{+}\right.$-ATPase) with bound potassium and ouabain. Proc Natl Acad Sci USA 2009; 106: 13742-7.

15 O‘Brien WJ, Lingrel JB, Wallick ET. Ouabain binding kinetics of the rat alpha two and alpha three isoforms of the sodium-potassium adenosine triphosphate. Arch Biochem Biophys 1994; 310: 32-9.

16 Morris JF, Ismail-Beigi F, Butler VP, Gati I, Lichtstein D. Ouabainsensitive $\mathrm{Na}^{+}, \mathrm{K}^{+}$-ATPase activity in toad brain. Comp Biochem Physiol A Physiol 1997; 118: 599-606.

17 Lebovitz RM, Takeyasu K, Fambrough DM. Molecular characterization and expression of the $\left(\mathrm{Na}^{+}, \mathrm{K}^{+}\right)$-ATPase alpha-subunit in Drosophila melanogaster. EMBO J 1989; 8: 193-202.

18 Rose AM, Valdes R Jr. Understanding the sodium pump and its relevance to disease. Clin Chem 1994; 40: 1674-85.

19 Gillis RA, Quest JA. The role of the nervous system in the cardiovascular effects of digitalis. Pharmacol Rev 1979; 31: 19-97.

20 Blanco G, Mercer RW. Isozymes of the Na-K-ATPase: heterogeneity in structure, diversity in function. Am J Physiol 1998; 275: F633-50.

21 Lingrel JB. Na,K-ATPase: isoform structure, function, and expression. J Bioenerg Biomembr 1992; 24: 263-70.

22 Lingrel JB. The physiological significance of the cardiotonic steroid/ ouabain-binding site of the Na,K-ATPase. Annu Rev Physiol 2010; 72: 395-412.

23 Blaustein MP. Physiological effects of endogenous ouabain: control of intracellular $\mathrm{Ca}^{2+}$ stores and cell responsiveness. Am J Physiol 1993; 264: C1367-87.

$24 \mathrm{Xie} \mathrm{Z,} \mathrm{Xie} \mathrm{J.} \mathrm{The} \mathrm{Na/K-ATPase-mediated} \mathrm{signal} \mathrm{transduction} \mathrm{as} \mathrm{a}$ target for new drug development. Front Biosci 2005; 10: 3100-9.

25 Xie Z, Cai T. $\mathrm{Na}^{+} / \mathrm{K}^{+}$-ATPase-mediated signal transduction: from protein interaction to cellular function. Mol Interv 2003; 3: 157-68.

26 Zhang L, Zhang Z, Guo H, Wang Y. $\mathrm{Na}^{+} / \mathrm{K}^{+}$-ATPase-mediated signal transduction and $\mathrm{Na}^{+} / \mathrm{K}^{+}$-ATPase regulation. Fundam Clin Pharmacol 2008; 22: 615-21.

27 Schonfeld W, Weiland J, Lindig C, Masnyk M, Kabat MM, Kurek A, et al. The lead structure in cardiac glycosides is 5 beta, 14 betaandrostane-3 beta 14-diol. Naunyn Schmiedebergs Arch Pharmacol 1985; 329: 414-26.

28 Melero CP, Medarde M, San Feliciano A. A short review on cardiotonic steroids and their aminoguanidine analogues. Molecules
2000; 5: 51-81.

29 Li-Saw-Hee FL, Lip GY. Digoxin revisited. QJM 1998; 91: 259-64.

30 Lin SC, Way EL. A high affinity $\mathrm{Ca}^{2+}$-ATPase in enriched nerve-ending plasma membranes. Brain Res 1982; 235: 387-92.

31 Blaustein MP. The interrelationship between sodium and calcium fluxes across cell membranes. Rev Physiol Biochem Pharmacol 1974; 70: 33-82.

32 Ferrandi M, Barassi P, Molinari I, Torielli L, Tripodi G, Minotti E, et al. Ouabain antagonists as antihypertensive agents. Curr Pharm Des 2005; 11: 3301-5.

33 Yang $\mathrm{Z}$, Luo $\mathrm{H}$, Wang $\mathrm{H}$, Hou $\mathrm{H}$. Preparative isolation of bufalin and cinobufagin from Chinese traditional medicine ChanSu. J Chromatogr Sci 2008; 46: 81-5.

34 Bick RJ, Poindexter BJ, Sweney RR, Dasgupta A. Effects of ChanSu, a traditional Chinese medicine, on the calcium transients of isolated cardiomyocytes: cardiotoxicity due to more than $\mathrm{Na}$, K-ATPase blocking. Life Sci 2002; 72: 699-709.

35 Lee E, Kim S, Chung KC, Choo MK, Kim DH, Nam G, et al. 20(S)ginsenoside $\mathrm{Rh} 2$, a newly identified active ingredient of ginseng, inhibits NMDA receptors in cultured rat hippocampal neurons. Eur J Pharmacol 2006; 536: 69-77.

36 Jia WW, Bu X, Philips D, Yan H, Liu G, Chen X, et al. Rh2, a compound extracted from ginseng, hypersensitizes multidrug-resistant tumor cells to chemotherapy. Can J Physiol Pharmacol 2004; 82: 431-7.

37 Chen Y, Zhan E, Chen H, Duan X, Guo L. Saponins with low sugar chain from the leaves of Panax notoginseng (Burk) $\mathrm{F} H$ Chen. Zhong Yao Cai 2002; 25: 176-8.

38 Lee IK, Kim DH, Lee SY, Kim KR, Choi SU, Hong JK, et al. Triterpenoic acids of Prunella vulgaris var lilacina and their cytotoxic activities in vitro. Arch Pharm Res 2008; 31: 1578-83.

39 Ryu SY, Oak MH, Yoon SK, Cho DI, Yoo GS, Kim TS, et al. Anti-allergic and anti-inflammatory triterpenes from the herb of Prunella vulgaris. Planta Med 2000; 66: 358-60.

40 Tan LL, Cai X, Hu ZH, Ni XL. Localization and dynamic change of saikosaponin in root of Bupleurum chinense. J Integr Plant Biol 2008; 50: $951-7$.

41 Zhou QL, Zhang ZQ, Nagasawa T, Hiai S. The structure activity relationship of saikosaponins and glycyrrhizin derivatives for $\mathrm{Na}^{+}, \mathrm{K}^{+}$ATPase inhibiting action. Yao Xue Xue Bao 1996; 31: 496-501.

42 Wang FS, Xu LX, Zhao YJ, Liu AR, Jin LZ, Zhang XQ. Determination of bile acids in bear gall drainage by thin layer chromatographic scanning. Yao Xue Xue Bao 1989; 24: 397-400.

43 Kurozumi K, Harano T, Yamasaki K, Ayaki Y. Studies on bile acids in bear bile. J Biochem 1973; 74: 489-95.

44 Liu Y, Chen W, Qiao C, Zhao N. Determination of sarsasapogenin in Anemarrhena asphodeloides Bunge by GC. Zhongguo Zhong Yao Za Zhi 1999; 24: 554-5, 75.

45 Fu WW, Hou WB, Dou DQ, Hua HM, Gui MH, Fu R, et al. Saponins of polygalacic acid type from Platycodon grandiflorum. Yao Xue Xue Bao 2006; 41: 358-60.

46 Zhang $\mathrm{M}$, Zhang $\mathrm{Y}$, Xie J. Simultaneous determination of jujuboside $\mathrm{A}, \mathrm{B}$ and betulinic acid in semen Ziziphi spinosae by high performance liquid chromatography-evaporative light scattering detection. J Pharm Biomed Anal 2008; 48: 1467-70.

47 Hennell JR, Lee S, Khoo CS, Gray MJ, Bensoussan A. The determination of glycyrrhizic acid in Glycyrrhiza uralensis Fisch ex DC (Zhi Gan Cao) root and the dried aqueous extract by LC-DAD. J Pharm Biomed Anal 2008; 47: 494-500.

48 Sun ZR, Zhai MP, Wang WQ, Li YR. Effects of density on seedling growth and glycyrrhizinic acid content in Glycyrrhiza uralensis. Zhongguo Zhong Yao Za Zhi 2007; 32: 2222-6, 81. Chinese. 
Biochim Biophys Acta 1994; 1200: 79-83.

49 Xu Q, Ma X, Liang X. Determination of astragalosides in the roots of Astragalus spp using liquid chromatography tandem atmospheric pressure chemical ionization mass spectrometry. Phytochem Analysis 2007; 18: 419-27.

50 Lin HC, Ding HY, Wu YC. Two novel compounds from Paeonia suffructicosa. J Nat Prod 1998; 61: 343-6.

51 Zhu TT, Liang H, Zhao YY, Wang B. Isolation and structure identification of $\mathrm{C}-25$ epimers of inokosterone from Achyranthes bidentata Blume. Yao Xue Xue Bao 2004; 39: 913-6. Chinese.

$52 \mathrm{Hu}$ T, Zhang X, Ma S, Cheng Y, Yao X. Chemical constituents from Corydalis yanhusuo. Zhongguo Zhong Yao Za Zhi 2009; 34: 191720. Chinese.

53 Zhang J, Jin Y, Liu Y, Xiao Y, Feng J, Xue X, et al. Purification of alkaloids from Corydalis yanhusuo W T Wang using preparative 2-D HPLC. J Sep Sci 2009; 32: 1401-6.

54 Zhang WB, Chen CX, Sim SM, Kwan CY. In vitro vasodilator mechanisms of the indole alkaloids rhynchophylline and isorhynchophylline, isolated from the hook of Uncaria rhynchophylla (Miquel). Naunyn Schmiedebergs Arch Pharmacol 2004; 369: 232-8.

55 Shi JS, Yu JX, Chen XP, Xu RX. Pharmacological actions of Uncaria alkaloids, rhynchophylline and isorhynchophylline. Acta Pharmacol Sin 2003; 24: 97-101.

56 Nakazawa T, Banba K, Hata K, Nihei Y, Hoshikawa A, Ohsawa K. Metabolites of hirsuteine and hirsutine, the major indole alkaloids of Uncaria rhynchophylla, in rats. Biol Pharm Bull 2006; 29: 1671-7.

57 Horie S, Yano S, Aimi N, Sakai S, Watanabe K. Effects of hirsutine, an antihypertensive indole alkaloid from Uncaria rhynchophylla, on intracellular calcium in rat thoracic aorta. Life Sci 1992; 50: 491-8.

58 Ozaki Y. Vasodilative effects of indole alkaloids obtained from domestic plants, Uncaria rhynchophylla Miq and Amsonia elliptica Roem et Schult. Nippon Yakurigaku Zasshi 1990; 95: 47-54. Japanese.

59 Oh H, Mun YJ, Im SJ, Lee SY, Song HJ, Lee HS, et al. Cucurbitacins from Trichosanthes kirilowii as the inhibitory components on tyrosinase activity and melanin synthesis of B16/F10 melanoma cells. Planta Med 2002; 68: 832-3.

60 Takahashi N, Yoshida Y, Sugiura T, Matsuno K, Fujino A, Yamashita U. Cucurbitacin D isolated from Trichosanthes kirilowii induces apoptosis in human hepatocellular carcinoma cells in vitro. Int Immunopharmacol 2009; 9: 508-13.

61 Badria FA, Mikhaeil BR, Maatooq GT, Amer MM. Immunomodulatory triterpenoids from the oleogum resin of Boswellia carterii Birdwood. Z Naturforsch C 2003; 58: 505-16.

62 Jayaprakasha GK, Mandadi KK, Poulose SM, Jadegoud Y, Nagana Gowda GA, Patil BS. Novel triterpenoid from Citrus aurantium L. possesses chemopreventive properties against human colon cancer cells. Bioorg Med Chem 2008; 16: 5939-51.

63 Zhang S. Chemical constituents of the Sparganium stoloniferum Buch.-Ham. Zhongguo Zhong Yao Za Zhi 1995; 20: 486-7. Chinese.

64 Zheng Y, Yang XW. Two new lanostane triterpenoids from Poria cocos. J Asian Nat Prod Res 2008; 10: 323-8.

65 Chen RJY, Chung TY, Li FY, Yang WH, Jinn TR, Tzen JTC. Steroidlike compounds in Chinese medicines promote blood circulation via inhibition of $\mathrm{Na}^{+} / \mathrm{K}^{+}$-ATPase. Acta Pharmacol Sin 2010; 31: 696702.

66 Li XC, Yu C, Sun WK, Liu GY, Jia JY, Wang YP. Pharmacokinetics of magnesium lithospermate $B$ after intravenous administration in beagle dogs. Acta Pharmacol Sin 2004; 25: 1402-7.

67 Shigematsu T, Tajima S, Nishikawa T, Murad S, Pinnell SR, Nishioka I. Inhibition of collagen hydroxylation by lithospermic acid magnesium salt, a novel compound isolated from Salviae miltiorrhizae Radix.
68 Lu Y, Foo LY. Polyphenolics of Salvia - a review. Phytochemistry 2002; 59: 117-40.

69 Wu XJ, Wang YP, Wang W, Sun WK, Xu YM, Xuan LJ. Free radical scavenging and inhibition of lipid peroxidation by magnesium lithospermate B. Acta Pharmacol Sin 2000; 21: 855-8.

70 Kasimu R, Tanaka K, Tezuka Y, Gong ZN, Li JX, Basnet P, et al. Comparative study of seventeen Salvia plants: aldose reductase inhibitory activity of water and $\mathrm{MeOH}$ extracts and liquid chromatographymass spectrometry (LC-MS) analysis of water extracts. Chem Pharm Bull 1998; 46: 500-4.

71 Yokozawa T, Chung HY, Dong E, Oura H. Confirmation that magnesium lithospermate $B$ has a hydroxyl radical-scavenging action. Exp Toxicol Pathol 1995; 47: 341-4.

72 Yokozawa T, Lee TW, Oura H, Nonaka G, Nishioka I. Effect of magnesium lithospermate $B$ in rats with sodium-induced hypertension and renal failure. Nephron 1992; 60: 460-5.

73 O K, Lynn EG, Vazhappilly R, Au-Yeung KK, Zhu DY, Siow YL. Magnesium tanshinoate B (MTB) inhibits low density lipoprotein oxidation. Life Sci 2001; 68: 903-12.

74 Tzen JT, Jinn TR, Chen YC, Li FY, Cheng FC, Shi LS, et al. Magnesium lithospermate $\mathrm{B}$ possesses inhibitory activity on $\mathrm{Na}^{+}, \mathrm{K}^{+}$-ATPase and neuroprotective effects against ischemic stroke. Acta Pharmacol Sin 2007; 28: 609-15.

75 Chen YC, Jinn TR, Chung TY, Li FY, Fan RJ, Tzen JT. Magnesium lithospermate B extracted from Salvia miltiorrhiza elevates intracellular $\mathrm{Ca}^{2+}$ level in SH-SY5Y cells. Acta Pharmacol Sin 2010; 31: 923-9.

76 Kulikov A, Eva A, Kirch U, Boldyrev A, Scheiner-Bobis G. Ouabain activates signaling pathways associated with cell death in human neuroblastoma. Biochim Biophys Acta 2007; 1768: 1691-702.

77 Zhu S, Zou K, Cai S, Meselhy MR, Komatsu K. Simultaneous determination of triterpene saponins in ginseng drugs by highperformance liquid chromatography. Chem Pharm Bull 2004; 52 : 995-8.

78 Dan M, Su MM, Gao XF, Zhao T, Zhao AH, Xie GX, et al. Metabolite profiling of Panax notoginseng using UPLC-ESI-MS. Phytochemistry 2008; 69: 2237-44.

79 Hasegawa $\mathrm{H}$. Proof of the mysterious efficacy of ginseng: basic and clinical trials: metabolic activation of ginsenoside: deglycosylation by intestinal bacteria and esterification with fatty acid. J Pharmacol Sci 2004; 95: 153-7.

80 Sengupta S, Toh SA, Sellers LA, Skepper JN, Koolwijk P, Leung HW, et al. Modulating angiogenesis: the yin and the yang in ginseng. Circulation 2004; 110: 1219-25.

81 Lei XL, Chiou GC. Cardiovascular pharmacology of Panax notoginseng (Burk) F H Chen and Salvia miltiorrhiza. Am J Chin Med 1986; 14: 145-52.

82 Cicero AF, Vitale G, Savino G, Arletti R. Panax notoginseng (Burk) effects on fibrinogen and lipid plasma level in rats fed on a high-fat diet. Phytother Res 2003; 17: 174-8.

83 Chen RJY, Chung TY, Li FY, Lin NH, Tzen JTC. Effect of sugar positions in ginsenosides and their inhibitory potency on $\mathrm{Na}^{+} / \mathrm{K}^{+}$-ATPase activity. Acta Pharmacol Sin 2009; 30: 61-9.

84 Nah SY, Kim DH, Rhim H. Ginsenosides: are any of them candidates for drugs acting on the central nervous system? Cns Drug Rev 2007; 13: 381-404.

85 Tawab MA, Bahr U, Karas M, Wurglics M, Schubert-Zsilavecz M. Degradation of ginsenosides in humans after oral administration. Drug Metab Dispos 2003; 31: 1065-71.

86 Shang HC, Gao XM, Guo LP. The optimization of different combinations and distributions between Danshen and Sanqi along with syn- 
thetical information evaluation. Drug Evaluation 2005; 2: 209-11. Chinese.

87 Li XC, Yu C, Cai YB, Liu GY, Jia JY, Wang YP. Simultaneous determination of six phenolic constituents of danshen in human serum using liquid chromatography/tandem mass spectrometry. J Chromatogr B 2005; 820: 41-7.

88 Tawab MA, Bahr U, Karas M, Wurglics M, Schubert-Zsilavecz M. Degradation of ginsenosides in humans after oral administration. Drug Metab Dispos 2003; 31: 1065-71.

89 Oian TX, Cai ZW, Wong RNS, Jiang ZH. Liquid chromatography mass spectrometric analysis of rat samples for in vivo metabolism and pharmacokinetic studies of ginsenoside Rh2. Rapid Commun Mass Sp 2005; 19: 3549-54.

90 Clausen T, Van Hardeveld C, Everts ME. Significance of cation transport in control of energy metabolism and thermogenesis. Physiol Rev 1991; 71: 733-74.

91 Friberg $\mathrm{H}$, Wieloch $\mathrm{T}$. Mitochondrial permeability transition in acute neurodegeneration. Biochimie 2002; 84: 241-50.

92 Astrup J. Energy-requiring cell functions in the ischemic brain. Their critical supply and possible inhibition in protective therapy. J Neurosurg 1982; 56: 482-97.

93 Annunziato L, editor. New strategies in stroke intervention. New York: Springer; 2009.
94 Wang JK, Portbury S, Thomas MB, Barney S, Ricca DJ, Morris DL, et al. Cardiac glycosides provide neuroprotection against ischemic stroke: discovery by a brain slice-based compound screening platform. Proc Natl Acad Sci USA 2006; 103: 10461-6.

95 Zhang YG, Liu TP. Influences of ginsenosides Rb1 and Rg1 on reversible focal brain ischemia in rats. Zhongguo Yao Li Xue Bao 1996; 17: 44-8.

96 Tian J, Fu F, Geng M, Jiang Y, Yang J, Jiang W, et al. Neuroprotective effect of 20(S)-ginsenoside Rg3 on cerebral ischemia in rats. Neurosci Lett 2005; 374: 92-7.

97 Zhou XM, Cao YL, Dou DQ. Protective effect of ginsenoside Re against cerebral ischemia/reperfusion damage in rats. Biol Pharm Bull 2006; 29: 2502-5.

98 Yuan QL, Yang CX, Xu P, Gao XQ, Deng L, Chen P, et al. Neuroprotective effects of ginsenoside $\mathrm{Rb} 1$ on transient cerebral ischemia in rats. Brain Res 2007; 1167: 1-12.

99 Chen LM, Zhou XM, Cao YL, Hu WX. Neuroprotection of ginsenoside Re in cerebral ischemia-reperfusion injury in rats. J Asian Nat Prod Res 2008; 10: 439-45.

100 Cho SO, Ban JY, Kim JY, Ju HS, Lee IS, Song KS, et al. Anti-ischemic activities of Aralia cordata and its active component, oleanolic acid. Arch Pharm Res 2009; 32: 923-32. 